Article

\title{
Endoscopic Botulinum Toxin for Gastroparesis: Results of a Retrospective Series
}

\author{
Fabiënne G. M. Smeets ${ }^{*}{ }^{\dagger}$, Denise Strijbos ${ }^{\dagger}$, Daniel Keszthelyi, Chantal V. Hoge, \\ Joanna W. Kruimel ${ }^{\mathbb{D}}$, José M. Conchillo and Ad A.M. Masclee
}

Division of Gastroenterology and Hepatology, Department of Internal Medicine, NUTRIM School of Nutrition and Translational Research in Metabolism, Maastricht University Medical Centre, P. Debyelaan 25,

6229 HX Maastricht, The Netherlands; denise.strijbos@catharinaziekenhuis.nl (D.S.);

daniel.keszthelyi@maastrichtuniversity.nl (D.K.); c.hoge@mumc.nl (C.V.H.); j.kruimel@mumc.nl (J.W.K.);

j.conchillo@mumc.nl (J.M.C.); a.masclee@mumc.nl (A.A.M.M.)

* Correspondence: fabienne.smeets@maastrichtuniversity.nl; Tel.: +314-3387-5021

+ These authors contributed equally to this work.

Received: 25 September 2018; Accepted: 11 December 2018; Published: 14 December 2018

\begin{abstract}
Beneficial effects of pyloric botulinum toxin injection have been described in a subgroup of gastroparesis patients. Our aim is to evaluate whether clinical, manometric and/or scintigraphic parameters are able to predict treatment outcome. Forty patients (67\% female, age 49 (36-56) years) with decompensated gastroparesis treated with botulinum toxin were included in this retrospective analysis. Objective parameters were high-resolution antroduodenal manometry, gastric emptying rate (scintigraphy), and weight change. Subjective treatment outcome was assessed with a Global Physician Assessment Scale. Binary logistic regression analysis was performed to identify predictors for treatment outcome. Fourteen patients ( $35 \%$ ) were symptom-responders, and $65 \%$ of patients were short-term weight-responders. For both subjective and objective treatment outcome, no differences were found in manometric and scintigraphic variables between responders and non-responders. Neither clinical nor manometric or scintigraphic variables could predict subjective and objective treatment outcome. In conclusion, symptom improvement is achieved in a subgroup of gastroparesis patients treated with endoscopic pyloric botulinum toxin. Although the majority of patients were able to maintain their baseline weight at short-term follow-up, a substantial group of patients needed nutritional interventions on long-term follow-up. However, none of the demographic, clinical, scintigraphic, or antroduodenal manometry variables were able to predict either subjective or objective treatment outcome.
\end{abstract}

Keywords: antroduodenal manometry; gastric emptying; gastroparesis; botulinum toxin; endoscopy; endoscopic treatment

\section{Introduction}

Gastroparesis is defined by delayed gastric emptying in the absence of a mechanical obstruction. It is associated with a wide variety of symptoms including nausea, vomiting, early satiety, postprandial fullness, upper abdominal pain, and bloating [1-4]. Common etiological factors are diabetes mellitus or vagal nerve injury after gastric surgery, although in the majority the cause remains unknown (i.e. idiopathic gastroparesis). Pathophysiological mechanisms include impaired gastric accommodation, antral hypomotility, disordered antroduodenal coordination, pyloric dysfunction and excessive inhibitory duodenogastric feedback [5-8].

Despite the increasing knowledge about pathophysiological mechanisms, management remains challenging. Initial treatment consists of dietary interventions and use of prokinetic agents $[9,10]$. 
In case of refractory symptoms, more invasive (endoscopic) and nutritional interventions are considered, including pyloric botulinum toxin [11,12].

Botulinum toxin $\mathrm{A}$ is a neurotoxic protein produced by the bacterium Clostridium botulinum which inhibits the release of acetylcholine at the neuromuscular junction. Pyloric botulinum injection decreases smooth muscle contractility and pyloric pressures [13-15]. Two small randomized placebo-controlled trials evaluated the effect of botulinum toxin in gastroparesis patients. Although both symptoms and gastric emptying improved after treatment with botulinum toxin, no significant difference was seen compared to placebo $[16,17]$. Consequently, treatment with botulinum toxin is currently not recommended by the American College of Gastroenterology (ACG) [11]. On the other hand, pyloric botulinum toxin is still regularly used in clinical practice because uniformly efficacious alternative treatment options are lacking. Previously, it has been hypothesized that treatment with botulinum toxin might be beneficial for at least a subgroup of gastroparesis patients. Gender, lower age and idiopathic gastroparesis proved to be clinical predictors for symptom improvement in one study, which findings were not reproduced in other studies $[18,19]$. Objective predictors for treatment outcome are currently not available. Therefore, we aimed to evaluate whether objective, manometric and/or scintigraphic parameters, in addition to clinical characteristics, are able to predict treatment outcome in patients with gastroparesis treated with pyloric botulinum toxin. We hypothesized that more severe delayed gastric emptying and/or antral hypomotility would be associated with a less favorable treatment outcome with both persistent symptoms and the inability to maintain body weight.

\section{Results}

\subsection{Patient Characteristics}

Between 2008 and 2016, 40 patients (67\% female, median age 49 (36-56) years) with decompensated gastroparesis were treated with endoscopic botulinum toxin injection. Baseline characteristics are shown in Table 1.

Table 1. Baseline characteristics.

\begin{tabular}{|c|c|}
\hline Characteristics & Median (IQR ${ }^{\ddagger}$ ) \\
\hline \multicolumn{2}{|l|}{ Demographic parameters } \\
\hline Age (years) & $49(36-56)$ \\
\hline Length $(\mathrm{cm})$ & $168(164-178)$ \\
\hline Weight before botulinum toxin $(\mathrm{kg})$ & $66.3(57-80)$ \\
\hline BMI before botulinum toxin $\left(\mathrm{kg} / \mathrm{m}^{2}\right)$ & $23.7(20.2-26.6)$ \\
\hline Etiology & $N(\%)$ \\
\hline Idiopathic & $17(42.5 \%)$ \\
\hline Diabetic & $13(32.5 \%)$ \\
\hline Post-surgical & $10(25 \%)$ \\
\hline $\mathrm{HbA} 1 \mathrm{C} *(\%)$ & $8.4(7.5-10.9)$ \\
\hline \multicolumn{2}{|l|}{ Gastric emptying parameters } \\
\hline T50 solid (min; normal 64-103 min) & $146(127-188)$ \\
\hline Stasis $60 \mathrm{~min}(\%$; normal $53-79 \%)$ & $89(82-91)$ \\
\hline Stasis $120 \mathrm{~min}(\%$; normal $16-37 \%)$ & $61(53-76)$ \\
\hline Stasis 240 min (\%; normal 0-4\%) & $17(2-31)$ \\
\hline \multicolumn{2}{|l|}{ Antroduodenal manometric parameters } \\
\hline Antral frequency (contractions/min) & $1.27(1.02-1.75)$ \\
\hline Antral amplitude $(\mathrm{mmHg})$ & $58(38-77)$ \\
\hline Antral Motility Index (MI) (mmHg) & $13.59(12.57-14.81)$ \\
\hline Antral hypomotility $\S(n, \%)$ & $14(53.8 \%)$ \\
\hline
\end{tabular}

$\S$ Antral hypomotility: postprandial motility index < $13.67 \mathrm{mmHg}$; BMI: body mass index; ${ }^{*} \mathrm{HbA1}$ c: glycated hemoglobin $(\mathrm{n}=11) ;{ }^{\ddagger} \mathrm{IQR}$ : interquartile range. 
Antroduodenal high-resolution manometry (ADM) was performed in 35 of the 40 patients (Figure 1). Twenty-six ADM measurements were eligible for analysis as predictive factor. Ineligibility was due to inability to determine correct positioning of the catheter on the basis of manometric recording $(n=4)$, and performance of ADM after previous treatment with botulinum toxin $(n=5)$.

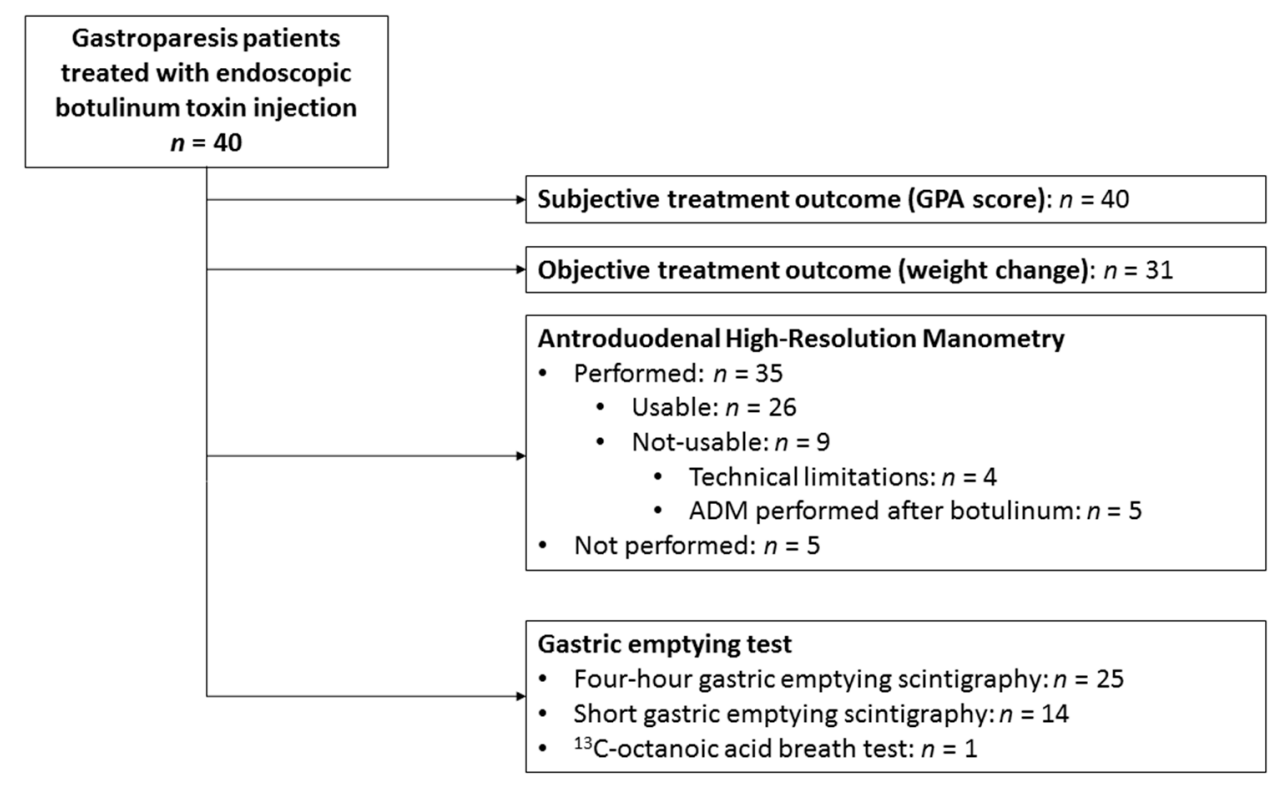

Figure 1. Flow chart of included gastroparesis patients.

\subsection{Subjective Treatment Outcome}

Based on the GPA score, 14 patients (35\%) were considered as symptom-responders whereas 26 patients (65\%) were non-responders (GPA 1: $2.5 \%$, GPA 2: $32.5 \%$, GPA 3: $2.5 \%$, GPA 4: $7.5 \%$, GPA 5: $55 \%$, GPA 6: $0 \%$ ). No correlations were found between subjective treatment outcome and manometric or scintigraphic variables. No differences were found in manometric and scintigraphic variables between symptom-responders and symptom-non-responders (data not shown).

The method of gastric emptying assessment, either (a) four-hour gastric emptying scintigraphy $(n=25)$ or (b) short gastric emptying scintigraphy or breath test $(n=15)$, was not associated with subjective treatment outcome (Fisher exact test: $p=0.91$ ). In addition, no differences were found in subjective treatment outcome between patients diagnosed with gastroparesis on the basis of (a) increased four-hour gastric retention $(40 \%)$, or (b) prolonged gastric half emptying time $(32 \%$; Fisher exact test $p=0.74$ ).

\subsection{Objective Treatment Outcome}

Before treatment with botulinum toxin, 12 patients had $<10 \mathrm{~kg}$ weight loss, whereas 14 patients had $\geq 10 \mathrm{~kg}$ weight loss. Seven patients had a stabile weight and no information was available for seven patients.

Weight change outcomes were available for 31 patients. Seventeen patients maintained their baseline weight (55\%); three patients showed weight gain $(10 \%)$ and weight loss occurred in eleven patients (35\%; two symptom-responders and nine symptom-non-responders). Overall, weight and BMI decreased after botulinum toxin treatment (weight: $67.0(58.0-80.0)$ to $65.0(57.0-78.0) \mathrm{kg}, p=0.03$; BMI: $23.9(20.5-26.5)$ to $\left.23.0(19.8-26.8) \mathrm{kg} / \mathrm{m}^{2}, p=0.01\right)$, and this decrease was most apparent in the symptom non-responder group (Table 2, data available for 30 patients). BMI before and after botulinum toxin treatment was lower in symptom non-responders compared to symptom-responders $(p<0.05 ;$ Table 2$)$. In addition, a negative correlation was found between symptom scores and BMI after botulinum toxin $(R=-0.42, p=0.02)$. 
Subjective and objective treatment outcome was available for 31 patients. Seven patients were considered both subjective and objective responders (23\%), whereas 13 patients were both subjective and objective non-responders ( $42 \%)$. The remaining patients were either only subjective $(6 \%)$ or objective responders $(29 \%)$. No association was found between subjective and objective treatment outcome (Fisher exact test: $p=0$. 67). In addition, no significant differences were found in patient characteristics, manometric and scintigraphic variables between weight-responders and weight-non-responders.

The method of gastric emptying assessment, either (a) four-hour gastric emptying scintigraphy $(n=25)$ or (b) short gastric emptying scintigraphy or breath test $(n=15)$, was not associated with objective treatment outcome (Fisher exact test: $p=0.71$ ). In addition, no differences were found in objective treatment outcome between patients diagnosed with gastroparesis on the basis of (a) increased four-hour gastric retention (58\%), or (b) prolonged gastric half emptying time (68\%; Fisher exact test $p=0.71)$.

Table 2. Body Mass Index (BMI) in symptom responders vs. symptom non-responders.

\begin{tabular}{cccc}
\hline & $\begin{array}{c}\text { BMI Before Botulinum } \\
\text { Toxin (Median; IQR) }\end{array}$ & $\begin{array}{c}\text { BMI after Botulinum } \\
\text { Toxin (Median; IQR) }\end{array}$ & $p$-Value \\
\hline Overall $(n=30)$ & $23.9(20.5-26.5)$ & $23.0(19.8-26.8)$ & 0.01 \\
Responders $(n=8)$ & $27.6(24.3-30.2)$ & $27.6(22.9-30.2)$ & 0.67 \\
Non-responders $(n=22)$ & $22.6(19.3-24.9)$ & $21.8(19.3-24.3)$ & $<0.01$ \\
\hline
\end{tabular}

IQR: interquartile range.

\subsection{Predictors}

Age, gender, weight, and BMI before botulinum toxin treatment, dose of botulinum toxin, and etiology of gastroparesis could not predict either subjective (Table 3) or objective treatment outcome (Table 4). In addition, baseline parameters from scintigraphy and antroduodenal manometry were not able to predict subjective (Table 3) or objective (Table 4) treatment outcome.

Table 3. Predictors for subjective treatment outcome * according to univariate binary logistic regression analysis.

\begin{tabular}{ccc}
\hline Parameters & Odds Ratio (95\% CI) & $p$-Value \\
\hline Age & $1.01(0.96-1.06)$ & 0.62 \\
Gender & $1.25(0.32-4.94)$ & 0.75 \\
\hline Etiology & & \\
\hline Idiopathic vs. non-idiopathic & $0.63(0.17-2.32)$ & 0.48 \\
Diabetic vs. non-diabetic & $0.80(0.20-3.16)$ & 0.75 \\
Post-surgical vs. non post-surgical & $2.67(0.48-14.79)$ & 0.26 \\
\hline Dose of botulinum toxin & $1.00(1.00-1.00)$ & 0.62 \\
Antral contraction frequency & $0.66(0.15-2.99)$ & 0.59 \\
Antral contraction amplitude & $0.99(0.96-1.03)$ & 0.71 \\
Antral motility index & $0.65(0.36-1.17)$ & 0.15 \\
Antral hypomotility & $5.25(0.50-54.91)$ & 0.17 \\
Gastric half emptying time (solids) & $1.00(0.99-1.01)$ & 0.85 \\
Gastric retention at 120 min & $1.01(0.94-1.08)$ & 0.84 \\
Gastric retention at 240 min & $1.00(0.95-1.04)$ & 0.81 \\
Weight before botulinum toxin & $1.04(0.98-1.10)$ & 0.24 \\
BMI before botulinum toxin & $1.15(0.97-1.36)$ & 0.11 \\
\hline
\end{tabular}

* Subjective treatment outcome: complete and marked symptom relief (GPA 1-2) after botulinum toxin treatment. BMI: body mass index. 
Table 4. Predictors for objective treatment outcome * according to univariate binary logistic regression analysis.

\begin{tabular}{ccc}
\hline Parameters & Odds Ratio (95\% CI) & $p$-Value \\
\hline Age & $1.02(0.96-1.08)$ & 0.56 \\
Gender & $0.40(0.08-1.90)$ & 0.25 \\
\hline Etiology & & \\
\hline Idiopathic vs. non-idiopathic & $2.23(0.50-10.00)$ & 0.30 \\
Diabetic vs. non-diabetic & $0.33(0.06-1.97)$ & 0.23 \\
Post-surgical vs. non post-surgical & $1.13(0.21-5.97)$ & 0.89 \\
\hline Dose of botulinum toxin & $1.00(1.00-1.00)$ & 0.92 \\
Antral contraction frequency & $0.47(0.10-2.11)$ & 0.32 \\
Antral contraction amplitude & $1.02(0.99-1.06)$ & 0.23 \\
Antral motility index & $0.98(0.56-1.69)$ & 0.94 \\
Antral hypomotility & $0.78(0.04-14.75)$ & 0.87 \\
Gastric half emptying time (solids) & $0.99(0.98-1.00)$ & 0.36 \\
Gastric retention at 120 min & $0.96(0.89-1.05)$ & 0.38 \\
Gastric retention at 240 min & $0.97(0.92-1.02)$ & 0.21 \\
Weight before botulinum toxin & $1.02(0.96-1.08)$ & 0.61 \\
BMI before botulinum toxin & $1.13(0.94-1.35)$ & 0.21 \\
\hline
\end{tabular}

* Objective treatment outcome: maintenance of baseline weight or weight gain after botulinum toxin treatment; BMI: body mass index.

\subsection{Follow-Up and Additional Treatment Procedures}

Repetitive botulinum toxin injections were performed in 13 patients (varying between 2-10 repeat treatments). Mostly, botulinum toxin treatment was repeated only in case the first treatment was successful. Four gastroparesis patients received a second treatment while the first treatment was not considered to be effective. Other treatment entities patients received are listed in Table 5. Forty-two percent of patients received additional nutritional interventions. Mean follow-up was 40 months.

Table 5. Additional treatment after botulinum toxin therapy.

\begin{tabular}{cc}
\hline Additional Treatment & $N(\mathbf{\%})$ (Total $n=40)$ \\
\hline Symptoms improved, no further treatment & $11(27.5)$ \\
Diet/prokinetics & $10(25.0)$ \\
Gastric rest and nasoduodenal tube & $6(15.0)$ \\
PEG-J & $10(25.0)$ \\
Laparoscopic jejunostomy & $1(2.5)$ \\
Unknown & $2(5.0)$ \\
\hline
\end{tabular}

PEG-J: Percutaneous Endoscopic Gastrostomy with jejunal extension.

\section{Discussion}

In this retrospective analysis, we evaluated single-center data on the clinical effect of endoscopic botulinum toxin injection in patients with decompensated gastroparesis. With respect to symptoms, improvement was reported by $35 \%$ of patients. A substantial group of patients were in need for additional nutritional interventions at long-term follow-up. We specifically sought for predictors of treatment outcome in order to be able to select subgroups of patients with beneficial effect of botulinum toxin treatment. It appeared that neither scintigraphic nor manometric nor clinical variables were helpful in predicting treatment outcome.

The symptomatic response rate of $35 \%$ we observed is comparable to previously described retrospective analyses $(43-51 \%)[18,19]$. In addition, a small randomized placebo-controlled trial described symptom improvement in $37 \%$ of patients after botulinum toxin treatment, whereas $56 \%$ patients reported symptom improvement after placebo [16]. Therefore, we have to take into account that the symptom improvement of $35 \%$ in the present study is affected by a placebo response. 
In addition, $35 \%$ of patients reported weight loss after a single botulinum toxin injection and $42 \%$ of patients eventually needed additional nutritional interventions. Interestingly, pre-treatment BMI was lower in symptom non-responders compared to symptom-responders, which could indicate more severe disease and/or reflect the importance of other pathophysiological factors. As treatment with botulinum toxin is expensive and has only a transient effect with need for repeated injections, identification of a subgroup of patients who will benefit from treatment with botulinum toxin is an important objective.

In the present study, we therefore attempted to identify predictors for both subjective and objective treatment outcomes. Several studies, including one retrospective analysis of 179 gastroparesis patients, investigated predictors for symptom improvement and found gender (with inconsistent results reporting either benefit for women or men), lower age, idiopathic gastroparesis, and dose of botulinum toxin to be predictors for symptom improvement $[18,19]$. We were not able to confirm these results: in our analysis none of the clinical demographic variables was able to predict treatment outcome. However, the smaller sample size in our study compared to that of Coleski et al. may have affected our results [18].

Apart from clinical predictors for treatment outcome, we hypothesized that more severe delayed gastric emptying and/or antral hypomotility would be associated with a less favorable treatment outcome with both persistent symptoms and inability to maintain weight. However, neither scintigraphic nor manometric parameters were able to predict either objective or subjective treatment outcome after botulinum toxin injection. In line with these results, Friedenburg et al. found no difference in gastric retention between patients with or without symptom improvement after botulinum toxin [16]. In addition, previous studies were not able to find a correlation between symptoms of gastroparesis and objective gastric emptying measured by scintigraphy [20-24]. One potential explanation for this lack of correlation is the fact that additional pathophysiological mechanisms apart from delayed gastric emptying (e.g. impaired gastric accommodation, visceral hypersensitivity, psychological factors, and comorbidity) contribute to symptom generation and perception [24]. These factors were not systematically assessed in the current study. Of note is that several prokinetic agents that are generally used for treatment of gastroparesis can also improve symptoms by antiemetic properties or by enhancing gastric accommodation [24].

Antral hypomotility has been described in a subgroup of gastroparesis patients [25]. In previous studies, several definitions have been used to describe antral hypomotility (i.e. postprandial motility index (MI) $<13.67 \mathrm{mmHg}$, antral contraction frequency $<1 / \mathrm{min}$ or antral contraction frequency $<2 / \mathrm{min}$ ) [26-28]. We hypothesized that botulinum treatment in patients with demonstrated antral hypomotility would be less beneficial compared to patients with retained antral motility. However, neither antral contraction frequency nor postprandial antral motility index were able to predict subjective and objective treatment outcome.

Pylorospasm, defined as the presence of episodes of unusually prolonged and intense tonic contractions of the pylorus, has been observed in $42-100 \%$ of patients with diabetic gastroparesis and was hypothesized to be an important target for endoscopic therapy of gastroparesis, as well as a potential predictor for treatment outcome $[6,11,15,29,30]$. Lacy et al. showed a reduction in pylorospasm in a group of diabetic gastroparesis patients treated with botulinum toxin [15]. In addition, Gupta et al. described a case report of a diabetic gastroparesis patient which showed marked reduction in isolated pyloric pressure waves (IPPWs) after botulinum toxin treatment [31-34]. Based on these observations, we were interested in analyzing pyloric tone and IPPWs in our cohort. Unfortunately, reliable assessment of pyloric tone by high-resolution solid state antroduodenal manometry was not feasible for two main reasons. First, catheter migration occurred frequently, which prevents accurate assessment of pyloric pressure especially as the pyloric width is considered to be only $0.6-2.1 \mathrm{~cm}$ and pressure transducers are located at $1 \mathrm{~cm}$ intervals [35]. Despite the use of frequent fluoroscopic examinations and metal clips to identify the pyloric region, catheter migration has also been described by Desipio et al. and it is considered one of the main concerns in HRM antroduodenal manometry [35]. 
Second, we were not able to reliably identify a high-pressure zone during phase I episodes, indicative for the pylorus, as previously described by two studies in healthy volunteers [35]. Consequently, we used the following characteristics to localize the pyloric region: (a) pressure tracing located between antral and small bowel pressure tracings during phase III, (b) fluoroscopic correlation to individual pressure transducers, and (c) manometric morphology representing a hybrid of antral and duodenal morphology. Therefore, we are not able to provide accurate results of pyloric pressure. In our opinion, currently available methodology does not allow prolonged reliable and reproducible recordings of the pyloric pressure zone. We were not able to support the statement of Herbella et al. that identification of the pylorus on HRM is easy and reliable [36].

Recently, evidence was found for impaired pyloric function in patients with gastroparesis using another technique: endoscopic functional luminal imaging probe (EndoFLIP). Two previous studies described decreased fasting pyloric compliance in gastroparesis patients compared to healthy controls, and widely varying results with regard to pyloric pressure, distensibility, and cross-sectional area in gastroparesis patients. In addition, hydraulic dilatation of the pylorus increased compliance, accelerated gastric emptying, and improved quality of life [7,37]. The hypothesis of an impaired pyloric function as a factor in gastroparesis is also supported by Wellington et al., who found evidence for a subgroup of gastroparesis patients with a functional obstructive phenotype with a normal gastric pacemaker rhythm. Treatment with either endoscopic botulinum toxin injection or balloon dilation in this group gastroparesis patients resulted in symptom improvement in $75 \%$ of patients [38]. These results support the hypothesis that improvement of pyloric compliance and/or cross-sectional area by endoscopic treatment options are able to improve symptoms [30]. Therefore, in the near future the EndoFLIP technique may help to identify a subgroup of gastroparesis patients with low pyloric distensibility and/or small diameter which might benefit from endoscopic botulinum toxin injection or other interventions aimed at reducing pyloric pressure, such as endoscopic myotomy (G-POEM) [39]. In fact, a positive clinical response to botulinum toxin injection could also serve to predict the response to G-POEM, but this issue remains to be elucidated.

Several limitations of our study should be mentioned. First, this study was retrospective in design and a Global Physician Assessment Scale was used to assess subjective treatment outcome instead of a validated patient-reported outcome measure. Consequently, individual symptoms were not assessed separately. In order to improve the accuracy of the GPA score, two researchers independently assessed GPA scores with a high concordance rate. Second, several diagnostic modalities were used for measurement of gastric emptying, whereas four-hour scintigraphy is considered the gold standard. Consequently, patients were diagnosed with gastroparesis in case of either increased four-hour gastric retention or prolonged gastric half emptying time. However, no association was found between the diagnostic method for assessment of gastroparesis (four-hour scintigraphy vs. short scintigraphy or breath test) or inclusion criterion (increased four-hour gastric retention or prolonged gastric half emptying time), and either subjective or objective treatment outcome. Third, the four-hour gastric emptying scintigraphy performed at our medical center differs with regard to meal content, and consequently reference values, from the consensus recommendation [40]. For future studies, use of the recommended gastric emptying scintigraphy is preferred although recent data described that only $3.1 \%$ of laboratories were compliant with the recommended protocol [41]. Fourth, high-resolution antroduodenal manometry did not allow us to reliably assess pyloric pressure and pylorospasm.

In conclusion, symptom improvement is achieved in a subgroup of gastroparesis patients treated with endoscopic pyloric botulinum toxin. Although the majority of patients were able to maintain their baseline weight at short-term follow-up, a substantial group of patients needed nutritional interventions on long-term follow-up. Moreover, none of the demographic clinical, scintigraphic, or antroduodenal manometric variables were able to predict either subjective or objective treatment outcome. We were, therefore, unable to provide substantiation for the use of botulinum toxin injections in gastroparesis. 


\section{Materials and Methods}

\subsection{Design, Setting, and Participants}

After institutional review board approval (METC 16-4-219; 9 Feburay 2017), we used patient medical records and our hospital's pharmacy database to retrospectively identify all patients with decompensated gastroparesis (Grade III, refractory to dietary interventions and medical therapy) who received treatment with botulinum toxin for gastroparesis between 2008 and 2016 in the Maastricht University Medical Center (MUMC+), a tertiary referral center [42,43].

\subsection{Scintigraphy}

Scintigraphy at MUMC+ was performed according to standard procedures developed at our hospital $[40,44]$. Medication affecting gastrointestinal tract motility was stopped at least three days prior to the study. After an overnight fast a standard meal was given to the patient, consisting of $100 \mathrm{~mL}$ egg whites mixed with ${ }^{99 \mathrm{~m}}$ Tc nanocolloïd (microwaved for $2 \mathrm{~min}$ ), one slice of bread with $15 \mathrm{~g}$ jam, and $120 \mathrm{~mL}$ radiolabelled ( ${ }^{111} \mathrm{In}$ DTPA) water (118 kcal, $12 \%$ fat, $77 \%$ carbohydrates, $11 \%$ protein). Patients were instructed to finish this meal within $10 \mathrm{~min}$. Immediately after meal ingestion, images were obtained $(t=0)$ as well as 60,120 , and $240 \mathrm{~min}$ after the meal.

\subsection{High-Resolution Antroduodenal Manometry}

Subjects underwent high-resolution antroduodenal manometry after an overnight fast of at least 8 hours. Medication affecting gastrointestinal tract motility was stopped three days prior to the study. A solid-state high-resolution catheter consisting of 36 transducers, spaced at 1-cm intervals, was used (Unisensor AG, Attikon, Switzerland). The catheter was advanced across the pylorus into the duodenum under fluoroscopic guidance with approximately 12 pressure sensors located into the stomach. After correct placement, the catheter leads were connected to the MMS working station (MMS Solar GI HRM, Medical Measurement Systems, Enschede, The Netherlands). The sampling frequency was $10 \mathrm{~Hz}$. After $30 \mathrm{~min}$ recording in fasting conditions, subjects were given a standardized meal consisting of one scrambled egg, two slices of white bread with $5 \mathrm{mg}$ of margarine, and $150 \mathrm{~mL}$ of water ( $283 \mathrm{kcal}, 41.2 \%$ fat, $17.1 \%$ carbohydrates, $41.6 \%$ protein). After ingestion of the meal, data were recorded for six hours, during which patients were not allowed to eat or drink.

\subsection{Endoscopic Pyloric Botulinum Toxin Injection}

After an overnight fast, patients underwent a standard upper gastrointestinal endoscopy under conscious sedation (midazolam $2.5-5 \mathrm{mg}$ intravenously). Botulinum toxin (abobotulinum toxin A, Dysport, Ipsen Farmaceutica bv, Hoofddorp, The Netherlands), at least 500IE diluted in $2.5 \mathrm{~mL}$ of saline, was injected in $0.6 \mathrm{~mL}$ aliquots in each quadrant of the pylorus using a sclerotherapy needle. The proposed conversion rate between Botox (onabotulinum toxin A) and Dysport seems to be 1:3, which means that one unit Botox is comparable to three units of Dysport [45].

\subsection{Outcomes}

Primary objective was to assess the relation between variables (scintigraphy and antroduodenal manometry) with both subjective and objective outcome parameters.

Subjective treatment outcome was assessed with a Global Physician Assessment Scale (GPA 1: complete relief; GPA 2: marked relief; GPA 3: moderate relief; GPA 4: slight relief; GPA 5: no relief; GPA 6: worsening symptoms), based on the clinical effect reported by the patient [46,47]. GPA was measured four weeks after botulinum toxin treatment or at the first control visit after treatment. Reported complete and marked relief (GPA 1-2) was considered as successful treatment. In order to improve the accuracy of the assessment of subjective treatment outcome, two reviewers independently 
evaluated the patients' charts and defined GPA-scores with a concordance rate of $98 \%$. Individual symptoms of gastroparesis (e.g., vomiting, nausea, postprandial fullness) were not assessed separately.

Change in weight after treatment with botulinum toxin injection was used as objective treatment outcome. Weight change was measured four weeks after botulinum toxin treatment or at the first control visit after treatment. Due to the small number of patients with weight gain after treatment, we considered both weight gain and maintenance of baseline weight as treatment success. Patients with weight loss were considered as non-responders. In addition, weight change before endoscopic treatment with botulinum toxin was described as either (1) stable weight, $(2)<10 \mathrm{~kg}$ weight loss or (3) $\geq 10 \mathrm{~kg}$ weight loss (measured approximately within six months prior to pyloric botulinum therapy).

\subsection{Data Analysis}

\subsubsection{Scintigraphy}

For the four-hour solid phase gastric emptying scintigraphy, total gastric counts were normalized to $100 \%$ for $t=0$ ( 0 min; image directly after meal ingestion). The percentage of contents remaining in the stomach was reported after 60, 120 and $240 \mathrm{~min}$. Normal gastric retention values were 53-79\% for $60 \mathrm{~min}, 16-37 \%$ for $120 \mathrm{~min}$, and $0-4 \%$ for $240 \mathrm{~min}$. Normal values for solid half emptying time were 64-103 min.

Fifteen patients were diagnosed with gastroparesis by a short scintigraphy test $(120 \mathrm{~min}, n=14)$, performed at the referring hospitals and/or ${ }^{13} \mathrm{C}$-octanoic acid breath test $(n=1)$. As comparison of different tests and/or study protocols is not possible, we only report quantitative results of the recommended four-hour solid phase gastric emptying scintigraphy $(n=25)$.

Patients were diagnosed with gastroparesis in case of (a) four-hour gastric retention of solids above the upper limit of normal, or (b) prolonged gastric half emptying time according to four-hour scintigraphy, short scintigraphy, or breath test.

\subsubsection{High-Resolution Antroduodenal Manometry}

After elimination of artefacts, the location of the individual pressure transducers was determined visually [35,36]. As a result of displacement of the catheter in several subjects, the localization of the individual pressure recordings had to be adjusted during analysis of the manometric data.

An increase in pressure of at least $10 \mathrm{mmHg}$ compared to baseline with a minimum duration of one second was considered a valid contraction and these contractions were included in automatic analyses. Although the postprandial period is defined as the interval between the start of the meal until the occurrence of the first duodenal phase III episode, we defined the postprandial period in all subjects as $120 \mathrm{~min}$ after intake of the standardized meal since not all subjects had a phase III episode at the end of the study [48]. Moreover, a postprandial period of $120 \mathrm{~min}$ seems to be acceptable as the occurrence of phase III within 60-90 min after ingestion of a meal provides evidence for failure to induce a fed pattern in subjects $[49,50]$.

During the postprandial period, we determined frequency of valid contractions (contractions per $\mathrm{min})$, contraction amplitude ( $\mathrm{mmHg}$ ) and motility index of antral pressure waves ( $\mathrm{mmHg})$. Motility index (MI) was calculated using the formula: $\mathrm{MI}=\ln ([$ number of waves $\times \Sigma$ amplitude $]+1)$ in the two pressure sensors located proximally to the manometrically- and fluoroscopically-defined pylorus, as previously described. Antral hypomotility was defined as a postprandial antral motility index $<13.67 \mathrm{mmHg}$ [26].

\subsection{Statistical Methods}

Data analysis was performed using SPSS for Windows, version 23 (IBM Corporation, Armonk, NY, USA). Non-parametric tests were used as several variables had no normal distribution. 
Data are presented as frequencies for categorical variables, and as median (interquartile range; IQR) for continuous variables. The $\chi^{2}$-test or Fisher's exact test (in case of small samples) was used to assess differences between categorical variables, whereas the Mann Whitney $U$ test and Kruskal Wallis test were used for continuous variables. The Spearman correlation coefficient $(R)$ was used to assess correlations between variables, and a binary univariate logistic regression analysis was performed to identify predictors for treatment outcome (odds ratio, 95\% CI). Patient characteristics, manometric and scintigraphic variables were used as potential predictors. All statistical tests were two-sided, with a significance level of 0.05 .

Author Contributions: Conceptualization: D.K and A.A.M.M; methodology: D.K. and A.A.M.M.; software: not applicable; validation: F.G.M.S., D.S., and D.K.; formal analysis: F.G.M.S., D.S., and J.M.C.; investigation: F.G.M.S., D.S., D.K., C.V.H., and J.M.C.; resources: not applicable; data curation: F.G.M.S., D.S., and C.V.H.; writing-original draft preparation: F.G.M.S. and D.S.; writing—review and editing: D.K., C.V.H., J.W.K., and A.A.M.M.; visualization: F.G.M.S., D.S., and D.K.; supervision: D.K., J.W.K., J.M.C., and A.A.M.M.; project administration: D.K. and A.A.M.M.; funding acquisition: not applicable.

Funding: This research received no external funding.

Conflicts of Interest: The authors declare no conflict of interest.

\section{References}

1. Shin, A.S.; Camilleri, M. Diagnostic assessment of diabetic gastroparesis. Diabetes 2013, 62, $2667-2673$. [CrossRef] [PubMed]

2. Abell, T.L.; Bernstein, R.K.; Cutts, T.; Farrugia, G.; Forster, J.; Hasler, W.L.; McCallum, R.W.; Olden, K.W.; Parkman, H.P.; Parrish, C.R.; et al. Treatment of gastroparesis: A multidisciplinary clinical review. Neurogastroenterol. Motil. 2006, 18, 263-283. [CrossRef]

3. Ali, T.; Hasan, M.; Hamadani, M.; Harty, R.F. Gastroparesis. South. Med. J. 2007, 100, 281-286. [CrossRef] [PubMed]

4. Parkman, H.P.; Hasler, W.L.; Fisher, R.S.; American Gastroenterological Association. American Gastroenterological Association technical review on the diagnosis and treatment of gastroparesis. Gastroenterology 2004, 127, 1592-1622. [CrossRef] [PubMed]

5. Camilleri, M.; Brown, M.L.; Malagelada, J.R. Relationship between impaired gastric emptying and abnormal gastrointestinal motility. Gastroenterology 1986, 91, 94-99. [CrossRef]

6. Mearin, F.; Camilleri, M.; Malagelada, J.R. Pyloric dysfunction in diabetics with recurrent nausea and vomiting. Gastroenterology 1986, 90, 1919-1925. [CrossRef]

7. Gourcerol, G.; Tissier, F.; Melchior, C.; Touchais, J.Y.; Huet, E.; Prevost, G.; Leroi, A.M.; Ducrotte, P. Impaired fasting pyloric compliance in gastroparesis and the therapeutic response to pyloric dilatation. Aliment. Pharmacol. Ther. 2015, 41, 360-367. [CrossRef]

8. Langworthy, J.; Parkman, H.P.; Schey, R. Emerging strategies for the treatment of gastroparesis. Expert Rev. Gastroenterol. Hepatol. 2016, 10, 817-825. [CrossRef] [PubMed]

9. Vanheel, H.; Vicario, M.; Vanuytsel, T.; Van Oudenhove, L.; Martinez, C.; Keita, A.V.; Pardon, N.; Santos, J.; Soderholm, J.D.; Tack, J.; et al. Impaired duodenal mucosal integrity and low-grade inflammation in functional dyspepsia. Gut 2014, 63, 262-271. [CrossRef] [PubMed]

10. Olausson, E.A.; Storsrud, S.; Grundin, H.; Isaksson, M.; Attvall, S.; Simren, M. A small particle size diet reduces upper gastrointestinal symptoms in patients with diabetic gastroparesis: A randomized controlled trial. Am. J. Gastroenterol. 2014, 109, 375-385. [CrossRef] [PubMed]

11. Camilleri, M.; Parkman, H.P.; Shafi, M.A.; Abell, T.L.; Gerson, L. Clinical guideline: Management of gastroparesis. Am. J. Gastroenterol. 2013, 108, 18-38. [CrossRef] [PubMed]

12. Ahuja, N.K.; Clarke, J.O. Pyloric Therapies for Gastroparesis. Curr. Treat. Options Gastroenterol. 2017, 15, 230-240. [CrossRef] [PubMed]

13. Lacy, B.E.; Weiser, K.; Kennedy, A. Botulinum toxin and gastrointestinal tract disorders: Panacea, placebo, or pathway to the future? Gastroenterol. Hepatol. 2008, 4, 283-295.

14. James, A.N.; Ryan, J.P.; Parkman, H.P. Inhibitory effects of botulinum toxin on pyloric and antral smooth muscle. Am. J. Physiol. Gastrointest. Liver Physiol. 2003, 285, G291-G297. [CrossRef] [PubMed] 
15. Lacy, B.E.; Crowell, M.D.; Schettler-Duncan, A.; Mathis, C.; Pasricha, P.J. The treatment of diabetic gastroparesis with botulinum toxin injection of the pylorus. Diabetes Care 2004, 27, 2341-2347. [CrossRef] [PubMed]

16. Friedenberg, F.K.; Palit, A.; Parkman, H.P.; Hanlon, A.; Nelson, D.B. Botulinum toxin A for the treatment of delayed gastric emptying. Am. J. Gastroenterol. 2008, 103, 416-423. [CrossRef] [PubMed]

17. Arts, J.; Holvoet, L.; Caenepeel, P.; Bisschops, R.; Sifrim, D.; Verbeke, K.; Janssens, J.; Tack, J. Clinical trial: A randomized-controlled crossover study of intrapyloric injection of botulinum toxin in gastroparesis. Aliment. Pharmacol. Ther. 2007, 26, 1251-1258. [CrossRef]

18. Coleski, R.; Anderson, M.A.; Hasler, W.L. Factors associated with symptom response to pyloric injection of botulinum toxin in a large series of gastroparesis patients. Dig. Dis. Sci. 2009, 54, 2634-2642. [CrossRef]

19. Bromer, M.Q.; Friedenberg, F.; Miller, L.S.; Fisher, R.S.; Swartz, K.; Parkman, H.P. Endoscopic pyloric injection of botulinum toxin A for the treatment of refractory gastroparesis. Gastrointest. Endosc. 2005, 61, 833-839. [CrossRef]

20. de Caestecker, J.S.; Ewing, D.J.; Tothill, P.; Clarke, B.F.; Heading, R.C. Evaluation of oral cisapride and metoclopramide in diabetic autonomic neuropathy: An eight-week double-blind crossover study. Aliment. Pharmacol. Ther. 1989, 3, 69-81. [CrossRef]

21. Horowitz, M.; Harding, P.E.; Maddox, A.F.; Wishart, J.M.; Akkermans, L.M.; Chatterton, B.E.; Shearman, D.J. Gastric and oesophageal emptying in patients with type 2 (non-insulin-dependent) diabetes mellitus. Diabetologia 1989, 32, 151-159. [CrossRef] [PubMed]

22. Keshavarzian, A.; Iber, F.L.; Vaeth, J. Gastric emptying in patients with insulin-requiring diabetes mellitus. Am. J. Gastroenterol. 1987, 82, 29-35.

23. Loo, F.D.; Palmer, D.W.; Soergel, K.H.; Kalbfleisch, J.H.; Wood, C.M. Gastric emptying in patients with diabetes mellitus. Gastroenterology 1984, 86, 485-494.

24. Janssen, P.; Harris, M.S.; Jones, M.; Masaoka, T.; Farre, R.; Tornblom, H.; Van Oudenhove, L.; Simren, M.; Tack, J. The relation between symptom improvement and gastric emptying in the treatment of diabetic and idiopathic gastroparesis. Am. J. Gastroenterol. 2013, 108, 1382-1391. [CrossRef] [PubMed]

25. Thazhath, S.S.; Jones, K.L.; Horowitz, M.; Rayner, C.K. Diabetic gastroparesis: Recent insights into pathophysiology and implications for management. Expert Rev. Gastroenterol. Hepatol. 2013, 7, 127-139. [CrossRef] [PubMed]

26. Thumshirn, M.; Bruninga, K.; Camilleri, M. Simplifying the evaluation of postprandial antral motor function in patients with suspected gastroparesis. Am. J. Gastroenterol. 1997, 92, 1496-1500. [PubMed]

27. Camilleri, M.; Hasler, W.L.; Parkman, H.P.; Quigley, E.M.; Soffer, E. Measurement of gastrointestinal motility in the GI laboratory. Gastroenterology 1998, 115, 747-762. [CrossRef]

28. Parthasarathy, G.; Ravi, K.; Camilleri, M.; Andrews, C.; Szarka, L.A.; Low, P.A.; Zinsmeister, A.R.; Bharucha, A.E. Effect of neostigmine on gastroduodenal motility in patients with suspected gastrointestinal motility disorders. Neurogastroenterol. Motil. 2015, 27, 1736-1746. [CrossRef]

29. Lacy, B.E.; Zayat, E.N.; Crowell, M.D.; Schuster, M.M. Botulinum toxin for the treatment of gastroparesis: A preliminary report. Am. J. Gastroenterol. 2002, 97, 1548-1552. [CrossRef]

30. Snape, W.J.; Lin, M.S.; Agarwal, N.; Shaw, R.E. Evaluation of the pylorus with concurrent intraluminal pressure and EndoFLIP in patients with nausea and vomiting. Neurogastroenterol. Motil. 2016, 28, 758-764. [CrossRef]

31. Gupta, P.; Rao, S.S. Attenuation of isolated pyloric pressure waves in gastroparesis in response to botulinum toxin injection: A case report. Gastrointest. Endosc. 2002, 56, 770-772. [CrossRef]

32. Deane, A.M.; Besanko, L.K.; Burgstad, C.M.; Chapman, M.J.; Horowitz, M.; Fraser, R.J. Modulation of individual components of gastric motor response to duodenal glucose. World J. Gastroenterol. 2013, 19, 5863-5869. [CrossRef] [PubMed]

33. Fraser, R.J.; Horowitz, M.; Maddox, A.F.; Dent, J. Postprandial antropyloroduodenal motility and gastric emptying in gastroparesis-effects of cisapride. Gut 1994, 35, 172-178. [CrossRef] [PubMed]

34. Heddle, R.; Dent, J.; Toouli, J.; Read, N.W. Topography and measurement of pyloric pressure waves and tone in humans. Am. J. Physiol. 1988, 255, G490-G497. [CrossRef] [PubMed]

35. Desipio, J.; Friedenberg, F.K.; Korimilli, A.; Richter, J.E.; Parkman, H.P.; Fisher, R.S. High-resolution solid-state manometry of the antropyloroduodenal region. Neurogastroenterol. Motil. 2007, 19, 188-195. [CrossRef] [PubMed] 
36. Herbella, F.A.; Aprile, L.R.; Patti, M.G. High-resolution manometry for the evaluation of gastric motility. Updates Surg. 2014, 66, 177-181. [CrossRef] [PubMed]

37. Malik, Z.; Sankineni, A.; Parkman, H.P. Assessing pyloric sphincter pathophysiology using EndoFLIP in patients with gastroparesis. Neurogastroenterol. Motil. 2015, 27, 524-531. [CrossRef] [PubMed]

38. Wellington, J.; Scott, B.; Kundu, S.; Stuart, P.; Koch, K.L. Effect of endoscopic pyloric therapies for patients with nausea and vomiting and functional obstructive gastroparesis. Auton. Neurosci. 2017, 202, 56-61. [CrossRef]

39. Jacques, J.; Pagnon, L.; Hure, F.; Legros, R.; Crepin, S.; Fauchais, A.L.; Palat, S.; Ducrotte, P.; Marin, B.; Fontaine, S.; et al. Peroral endoscopic pyloromyotomy is efficacious and safe for refractory gastroparesis: Prospective trial with assessment of pyloric function. Endoscopy 2018. [CrossRef]

40. Abell, T.L.; Camilleri, M.; Donohoe, K.; Hasler, W.L.; Lin, H.C.; Maurer, A.H.; McCallum, R.W.; Nowak, T.; Nusynowitz, M.L.; Parkman, H.P.; et al. Consensus recommendations for gastric emptying scintigraphy: A joint report of the American Neurogastroenterology and Motility Society and the Society of Nuclear Medicine. Am. J. Gastroenterol. 2008, 103, 753-763. [CrossRef]

41. Farrell, M.B.; Costello, M.; McKee, J.D.; Gordon, L.L.; Fig, L.M. Compliance with Gastric-Emptying Scintigraphy Guidelines: An Analysis of the Intersocietal Accreditation Commission Database. J. Nucl. Med. Technol. 2017, 45, 6-13. [CrossRef] [PubMed]

42. Parkman, H.P.; Fass, R.; Foxx-Orenstein, A.E. Treatment of patients with diabetic gastroparesis. Gastroenterol. Hepatol. 2010, 6, 1-16.

43. Hasler, W.L. Gastroparesis-current concepts and considerations. Medscape J. Med. 2008, 10, 16.

44. Szarka, L.A.; Camilleri, M. Methods for measurement of gastric motility. Am. J. Physiol. Gastrointest. Liver Physiol. 2009, 296, G461-G475. [CrossRef] [PubMed]

45. Scaglione, F. Conversion Ratio between Botox ${ }^{\circledR}$, Dysport ${ }^{\circledR}$, and Xeomin ${ }^{\circledR}$ in Clinical Practice. Toxins 2016, 8, 65. [CrossRef] [PubMed]

46. Hanauer, S.; Schwartz, J.; Robinson, M.; Roufail, W.; Arora, S.; Cello, J.; Safdi, M. Mesalamine capsules for treatment of active ulcerative colitis: Results of a controlled trial. Pentasa Study Group. Am. J. Gastroenterol. 1993, 88, 1188-1197. [PubMed]

47. Strijbos, D.; Keszthelyi, D.; Masclee, A.A.M.; Gilissen, L.P.L. Percutaneous endoscopic colostomy for adults with chronic constipation: Retrospective case series of 12 patients. Neurogastroenterol. Motil. 2018, 30, e13270. [CrossRef] [PubMed]

48. Bortolotti, M.; Annese, V.; Coccia, G. Twenty-four hour ambulatory antroduodenal manometry in normal subjects (co-operative study). Neurogastroenterol. Motil. 2000, 12, 231-238. [CrossRef] [PubMed]

49. Quigley, E.M.; Donovan, J.P.; Lane, M.J.; Gallagher, T.F. Antroduodenal manometry. Usefulness and limitations as an outpatient study. Dig. Dis. Sci. 1992, 37, 20-28. [CrossRef]

50. Verhagen, M.A.; Samsom, M.; Smout, A.J. Gastric myoelectrical and antroduodenal motor activity in patients with achalasia. Neurogastroenterol. Motil. 1998, 10, 211-218. [CrossRef]

(c) 2018 by the authors. Licensee MDPI, Basel, Switzerland. This article is an open access article distributed under the terms and conditions of the Creative Commons Attribution (CC BY) license (http://creativecommons.org/licenses/by/4.0/). 